\title{
REMIR E REMITTIR E SEUS PROPINQUOS
}

«Sans la langue, en un mot, l'auteur le plus divin»

«Est toujours, quoiqu'il fasse, un méchant écrivain.»

Bolleau.

«Scientia a verborum signíficatione incipit.»

ALTIN. DE NLL. SENT. T. I. R. I. n. $^{\circ} 3$

$\mathrm{Na}$ decadencia em que vai-se abysmando para o seio das trevas a lingua latina, muito trabalho hão de ter as gerações por vir, si não houver de quando em quando um Stentor que brade á etymologia, que evoque as origens, que excave as raizes das palavras creadas e cultivadas pelo povo romano, transmittidas até nós através dos mares revoltos de muitas civilisações.

Nada apparentemente mais facil do que differir ou discriminar as palavras remir e remittir, verbos consagrados nos idiomas oriundos do latim. Nem ha lingua neo-latina que não contenha uma variedade de termos propinquos daquelles dois verbos.

\section{REMIR OU REDIMIR}

Redimir é litteral traducção de redimere, composto de re-emere ou ainda retro-emere.

A particula re denota repetição; e a particula retro denota retroacção. Uma e outra podem-se ac- 
ceitar na composição de redimir. Preferimos re a retro. Quer dizer que redinnir implica o conceito de tornar a comprar, de tornar a adquirir, de pagar a dinheiro ou em especie uma coisa que é nossa, mas que uma contingencia qualquer está levando para fora de nosso patrimonio.

O cidadão nosso, captivo do inimigo, é redimido; isto é, é adquirido novamente ou a preço de oiro ou em troca de uutro prisioneiro que em nosso poder estava.

O executado que tem seus bens penhorados e que vão ser excutidos por hasta publica, comparece em juizo e exhibe o valor delles, ou no acto da arrematação offerece a quantia pela qual vão ser alienados em concurrencia publica.

Este acto do executado, que occorre a liberar - que é seu, mas que, apezar de seu, vai-lhe escapando por via judicial, eis a significação de redimir. $\mathrm{O}$ executado adquire de novo os bens, e estes se dizem redimidos, quasi como re-comprados.

Outro qualquer adquirente ou licitante, que não seja o executado ou algum de seus herdeiros, se diz que compra em hasta publica ou arremata, mas não se diz que redime.

O remir ou redimir é proprio do dono ou quasi dono; é proprio da patria com seus filhos; do partido politico ou guerreiro a respeito dos homens de seu bando.

As palavras parentas de remir são redempscão, o acto de remir; reminte on rediminte o que practica a redempção; remido ou redempto o que foi beneficiado pela redempção. 


\section{$-73 \rightarrow$}

\section{Entre parenthesis:}

Com quanto não parentas, são de identica força ou perfeita synonymia os termos resgatar, resgate, resgatante, resgatado.

Confirmemos com Vieira a synonymia de redempção e resgate.

«O sangue de Christo foy o preço «de nossa Redempção; e como este "preço era infinito, porque uma só "gotta bastava para remir mil mundos, «tão infinito foi o que sobejou depois «de remido, como infinito era o que «se despencleu para o remir. E que se «fez deste preço que sobejou? Assi «como do que se despendeu se pagou «o resgate; assi do que sobejou se fez «um deposito.»

Vieira. Serm. I. 995.

Deste mysterio da Redempção, uma das mais consoladoras verdades do catholicismo, em que figura o sangue de J. C. de preço e preço importante, que valha e compense os homens todos, nasceu, era natu. ral, o modo tão commum e translato de dizer remir a culpa.

Dizer que alguem remio a culpa ou o peccado é o mesmo que affirmar ter practicado tantas e boas acções, que mereceu de Deus e dos homcins commiseração.

Em outros termos é ter adquirido tantos merecimientos que valham na balança da justiça o peso do peccado. 
REMITTIR

Remittir é do latim remittere, mittere re ou retro, mandar atraz. Remittere deu ao portuguez remetter $\mathrm{e}$ remittir.

Remetter é vulgar, é palavra que não necessita de explicação alguma, tão evidente se depara.

Remittir não é vulgar. E' palavra quasi exclusiva a linguagem do Direito, da Medicina e da Theologia. Em qualquer destas sciencias, porem, em que $\cap$ termo se empregue, vê-se logo o cunho da etymologia, percebe-se claro a estirpe donde procedem os rebentos.

De mittere re ou retro, mandar atraz, é facil derivar estas outras accepções:-ajroixar ou descontinuar, relaxar, fazer com intercadencia, abrir mão, abandonar perdoar.

O que manda atraz não continua, é a primeira significação ou consequencia do acto.

O que descontinua relaxa physicamente ou bamba; e da significação material passa-se á moral, passa-se ao relaxamento como synonymo de desidia.

De bambar ou relaxar para fazer com intercadencia é um só passo. $\mathrm{E}$ as intercadencias de uma obra, desde que se prolonguem ou se amiudem, trazem o resultado do abandono, que $\ell$ o abrir mão. E quem abre mão do direito de punir perdoa.

Exemplo de abandonar é aqu(lla passagem de Fr. Luiz de Souza:

« Remittia muytas cousas á força da palavra «divina, acomodando suas pregações á natureza dos «ouvintes e os conceitos dellas á calidade das culpas «que avia.»

Vida do Arc. L. III C. XIII. 
A concatenação que estabelecemos é natural e logica sem um só vinculo forçado. Prendem-se os anneis da cadeia com uma tal precisão que o menos perspicaz linguista percebe em todos os passos urna feição do verbo REMTTTERE.

No sentido medico.

Usa-se activa e neutramente. Ex:

«A febre durou dois dias sem remittir. A febre «poucas vezes remitte: ordinariamente é continua e «sustentada.»

Dahi o nome de febre remittente a que apresenta remissões.

Remissão em materia medica define-se: «Cessação mais ou menos completa dos symptomas febris; ou ainda em sentido geral: "Diminuição temporaria dos symptomas de uma doença, quer aguda, quer chronica.»

Littré Dic. de Méd. Verbo Remission.

$\mathrm{O} \mathrm{P}^{\circ}$ Vieira mestre primaz da nossa lingua, hoje tão menosprezada, tambem usa de remittir em sentido neutro e com um só t, conforme a graphica de seu tempo.

«Espero que com a mudança e melhoria do lúgar tenhão (os achaques) remitido de tod:s, e V. S. esteja restituido á inteira saude.

Vieira. Cartas. I. 233.

O adverbio de todo dá ao verbo remittir no caso vertente um augmento de intcasidacle, levando-o a significar cessação. 
Já os latinos no sentido medico usaram remittere activa e neutramente.

Forcelini, Totrus Latinitatis Lexicon, verbo remittere, no fim, traz o seguinte:

Remittir-se (forma passiva) ou absolutamente remittir applica-se á molestia que se acalma ou decresce.

E accrescenta este éxemplo:

" Cum remiserant dolores pedum, non deerat in «causis. Como tinham-se remittido as dores dos pés, «não faltava ao tribunal.»

No sentido theologico:

Remittir é perdoar. Já Forcelini, obra citada, diz assim:

«Remittere tambem quer dizer ignoscere, perdoar. "Remittere injuriam é de Sallustio: Remittere culpam «é de Valerio Flacco.»

Nas Sagradas Lettras os exemplos são innumeros.

Christo ao paralytico: «H气mo, remittuntur tibi "peccata tua. Homen, teus peccados são perdoados.»

Luc. V 20.

E David no psalmo XXXI, principio: «Beati, «quorum remissae sunt iniquitates. Bem aventurados «aquelles cujas iniquidades foram pcrdoadas.» 
No sentido juridico:

Forcelini, explanando as multiplas significações de remittere, isto affirma:

¿Et saepe de iis dicitur quae debentur: cui con. «trarium est exigere. Frequentemente applica-se ás "coisas que são devidas: neste caso é o contrario de «exigir.»

E exemplifica: «Pecunias, quas erant in publi"cum Varroni cives R. polliciti, remittit. Remitte (isto «é não exige) os dinheiros que publicamente os cida«dãos romanos haviam promettido a Varrão.»

Não exigir é afinal de contas abrir mão, largar ou abandonar e não cogitar mais. E' fazer ás pessoas, vinculadas comnosco por obrigação, o mesmo que o Poder Publico aos compromettidos em crimes politicos: esquecer de todo e não indagar mais.

O remittir do direito civil e o amnistiar do direito politico

Pedro, proprietario, tomava contas em juizo a Paulo, gestor de seus negocios. Sinão quando, de motu proprio ou por influencia de outrem, não quer mais Pedro averiguar contas nem destrinçar miudezas afim de apurar a responsabilidade de seu administrador; mas ao contrario resolve com um só acto impor silencio ao processo. Faz lavrar a favor de Paulo um termo, no qual remitte toda e qualquer obrigação de Paulo que porventura se pudesse verificar, ficando ipso facto tambem extinctu o processo de tomada de contas.

Paulo por esse termo, quite com seu patrão, é remittido de todá responsabilidade. Dir-se-ha com 
mais propriedade num caso destes que Paulo obteve remissão do credor e não perdão.

O perdão supporia que Pedro averiguou os acontecimentos, pesquizou os gastos, rebuscou os assentos e chegou a apurar em factos precisos a responsabilidade de Paulo. $O$ perdão lança ao esquecimento a culpa certa de pessoa tambem certa.

A remissão expunge as indagações, abre mão de averiguar até onde vai a culpa e não quer saber quem é o culpado.

$O$ perdão acciona um direito restricto em um campo de limites visiveis. A remissão acciona ou pode accionar até um direito ainda vago e expande-se por um horizonte de mal difinidos ou interminos contornos.

Remittir comprehende em si o perdoar. Este é, porque assim digamos, uma especie daquelle genero.

Remittir é o quitar dos quinhentistas:

« Nenhum Vereador quite coima, nem pena «alguma a pessoa que em ella tenha incorrido, nem «divida, nem outra coisa que ao Conselho se deva.»

Ord. Liv. I, tit. 66, I 9.

Temos nesta passagem a latitude do verbo quitar perfeitamente caracterisada e irmanada á signifificação de remittir. A saber:-quitar coima, (synonymo de mulcta); quitar pena; quitar divida; e finalmente quitar qualquer obrigação.

\section{PALAVRAS DERIVADAS OU PARENTAS}

De remittir, como é obvio, nasce remittente, nasce remisso, nasce remissão.

Remittente, afora a significação medica de que falamos, é termo juridico, que significa a pessoa que remitte ou o sujeito que exerce remissão. 


\section{$-79$.}

A palavra remissão-remissio-é da latiniảade classica, como o verbo remittere, e não tern outra significação que não seja a acção daquelle verbo.

REMISSÃo jamais significou redempcãa ou resgati.

Eis o poncto de nossa dissertação. Eis o alvo que queremos ferir com este nosso estudo, provando como se tem errado copiosamente na technica juridica o emprego da palavra REMISSÃo, que por morio algum, em nenhum tempo e nenhum caso, pode ser parenta de remir.

$$
*^{*} *
$$

O interesse de deslindar as raias de cada qual dos verbos remir e remittir não é só o linguistico.

Remissão, substantivo de remittir, entra necessariamente e a cada passo nas locuções da jurisprudencia.

Ninguem que reflicta um momento na elocução deixa de perceber que do verbo remir o substantivo propinquo é redempção; mas as nossas leis e jurisconsultos tem erradamente usado remissão, em vez de redempção com detrimento da clareza da phrase e postergação da technica juridica. Escudemo-nos no texto de Boileau, vindo a nosso ver tanto ao proposito, e prosigamos.

$$
* * *
$$

REmiss Ão. "E" licito a qualquer renunciar o seu «direito ou remittir e perdoar as prestações que the «são devidas, excepto nos casos em que a lei o pro«hibir.»

Cod. Civ. Port. art. 8 I 5 . 
«A restituição da coisa empenhada presuppõe a «remissão do direito ao mesmo penhor, si o credor «não provar o contrario.»

Id. id. $87 \mathrm{I}$.

«Da remissão do penhor não resulta a pre«sumpção da remissão da divida.»

Id. id. 872 .

Reparemos para o emprego aqui feito dos vocabulos remittir e remissão, postos nessas phrases com. o valor precisamente juridico: abrir mão, renunciar

Continuemos:

«Il n'importe de quelle manière la dette ait été «éteinte, soit par le payement réel, soit par la rémise «que le créancier en fait à son débiteur, etc. etc.»

Troplong. Hyp. I. 846.

«RÉmise, diz o eminente Littré, abandon que «l'on fait à un débiteur d'une partie de ce qu'il «doit.»

E Larousse na Encyclopedia, verbo rémise, art. jurisprudencia, diz que a remissão, isto é o abandono do credito, pode ser feito a titulo gratuito ou a titulo oneroso.

Dá-se este caso, quando o credor recebe um outro objecto em pagamento ou uma outra obrigação: é um caso de dação in solutum. Dá-se a remissão a titulo gratuito quando pelo abandono nada recebe o devedor: é uma liberalidade.

Vê-se que é esta mesma a significação nossa na jurisprudencia. $O$ abandono a titulo gratuito podese perfeitamente traduzir por perdão na nossa linguagem vulgar. 
O Diccionario Imperial da Lingua Ingleza, obra cujos meritos ninguem poderá exaggerar, verbo $R e$ mission, diz o seguinte: "Discharge or relinquishment «of a debt, claim or right.»

E mais adiante em outra significação accrescenta: "The act of forgiving; forgivness.; pardon.»

$\mathrm{O}$ que tudo tem perfeito cabimento no nosso idioma com litteral traducção, tudo derivado do latim, ape $a r$ de não ser o inglez oriundo do Lacio.

«Desencargo ou derelicção de um debito, prè«tenção ou direito.»

«O acto de esquecer; esquecimento, perdão'»

Innumeros textos do Dir. Rom. podem ser trazidos a corroborar nossa affirmativa de ser insubstituivel a palavra remissão no vocabulario juridico.

Demos uns exemplos.

«Nec acquiri libertas, nec remitti

servitus per partem potest.»

De serv. praed. rust.

"Actiones suas remittentibus non est

dandus ad eas regressus.»

Aphor.

«Fus publicum nemo remittere potest.»

Fr. I $\S 70^{\circ}$ Dig. 26.

De Adm. et per. tut.

«Entre os modos de extincção da servidão um «é a remissão.»C. da Rocha. Verbo Servidões.

Quer dizer aqui a renuncia, o abrir mão do direito, quer de um modo tacito não fazendo uso delle por tão largo tempo que induza perdimento, quer 
expressamente declarando não querer mais aquelle direito.

Outro exemplo:- - Requerendo $F$ que se lhe «confirmasse a remissão do foro de umas casas que «lhe havia feito o Senado da Camara, foi indeferida «eșta petição, por não ter o Senado jurisdicção para «conceder taes remissões, etc.»

B. Carneiro. L. I. Tit. XXXVII. Nota $\S 3$ I 6.

O Marechal F. Peixoto, na mensagem sobre negocios militares, dirigida em 3 de Outubro de 1894 ao Congresso, apezar de estar mui longe de ser auctoridade linguistica e menos ainda juridica, assim se exprimio quasi no final della: «Pela connexão do as«sumpto proponho tambem decreteis a remissão da «divida á Fazenda Nacional, deixada pelos funcciona«rios civis ou militares, que succumbiram no serviço «da Republica.»

Ninguem deixa de ver com evidencia que remittir o foro e remittir a divida é o mesmo que não exigil-os, significação mui bem frisada por Forcellini retrocitado, quando diz que, em se tractando de obrigações, remittir é o contrario de exigir.

$$
*^{*} *
$$

Si remissão outra coisa não é que o esquecimento da obrigação, esquecimento practicado pelo credor a favor do devedor, como se explica a palavra REMISSÃo posta por epigraphe a um capitulo da Lei Hypothecaria de $\mathrm{i} 864$, reproduzida na de I890?!

Como se explica que tractadistas de notavel sciencia, como Lafayette, reproduzem em seus escriptos a mesma locução? 
Evidentemente errou o primeiro que tal escreveu. $\mathrm{E}$, como é facil e natural, e até certo poncto honroso, apoiar a opinião propria na auctoridade de Homero e outros maiores, é claro que tendo dormitado o primeiro Homero que tal erro consagrou, os demais seguiram-lhe a trilha dormitando á influencia do mesmo somno.

O que as leis hypothecarias erradamente chamaram remissão nada mais, nada menos é que a redempção ou resgate do immovel hypothecado. Tal é o caso:--o adquirente do immovel hypothecado, do immovel gravado, paga ao credor o preço do vinculo, o preço do gravame ou encargo que está onerando a propriedade recem-adquirida.

Como hypotheca é principio de alienação, temos neste caso a acção precisa do verbo remir, que vale tanto como re-comprar, readquirir aquillo que é nosso, mas que as contingencias especiaes do onus hypothecario estão pondo fora do nosso patrimonio.

Este mesmo conceito podiamos exprimir pelas palavras latino-lusitanas expurgar e liberar.

Expurgar diz sempre o Cod. Civ. Portuguez.

Purgement dizem os francezes.

Bem que a palavra regaste, cujo valor já de relance aquilatamos, traduza com adequação irreprehensivel a idea, somos de parecer que deveriamos sagrar o verbo liberar e o substantivo liberamento ou liberação. 
Ninguem arrepender-se-ha de perder alguns minutos na leitura dos arts. 938 a 948 , sujeitos á epigraphe - Da eXPURGaÇão DAS hYPOTHECAS-do Cod. Civ. Portuguez.

Alli se vê todo o phenomeno do liberamento das hypothecas, operado por acção do adquirente do predio gravado, mais ou menos tractado como em nosso direito; mas em vez do termo errado remissão, usa o Codigo expurgar e expurgaşão com toda a mais concomittante phraseologia sempre apropositada á indule latina, á força etymologica, ao valor technico juridico.

Si rebuscarmos com certo tento a razão porque os tractadistas e legisladores usaram tão erradamente remissão em vez de redempção ou resgate, talvez cheguemos á conviç̧ão de que quizeram derivar esse substantivo do verbo remir. Foram porem de uma infelicidade, valha o euphemismo, forra de toda marca! Não indaguemos quem foi o batedor, quem foi o bandeirante desta façanha!

Ella não excitará a inveja de ninguem, como de presente não aguilhoa a nossa curiosidade.

Do verbo remir não precisava a lingua portugueza derivar substantivo algum, porque já os latinos de redemptio deram-nos redempção, proximamente vindo do verbo redimo, redimir, donde temos redemptor, redempto, rediminte.

Em toda hypothese, quem não se contentasse com a opulencia já consolidada da lingua portugueza e quizesse á pura força arrancar um substantivo de remir, não devia tirar remissão, vocabulo que já exis- 
tia ha mais de dois mil annos com sua significaçã̀o immutavel, enkystada pelos seculos.

Mas devia crear remição como propinqua de redemptio, já que a mutação do ti das terminações latinas se faz para ção e nunca para ssão.

Exemplos:-conditio, condição; actio, acção; redemptio, redempção; e assim de ceteris invariavel. mente.

Entretanto, tambem invariavelmente, a terminação ssio latina transmuda-se ao portuguez em ssão, como permissio, permissão; pressio, pressão; concussio, concussão, e assim por diante.

A locução-Remissão DA HYPOTHECA assim posta nas leis e nos tractados de direito civil não só re. pugna em absoluto á origem ou etymologia das palavras e á vernaculidade do nosso idiorna, como até affronta de perto o sentido juridico com que as palavras já nos vieram cunhadas pelo sinete do tempo.

Si de facto a jurisprudencia deu assento a remittir e remissão, não só a jurispruclencia romana, como as outras, segundo rapidamente esboçamos, como é que sém alguma necessidade, ao contrario com menospreço de palavra:; elegantes provindas do latim, tracta-se nas leis hypothecarias o phenomeno de remir ou resgatar predios gravados com a expressão remissão da hypotheca?

Finalisemos.

Remissão, como já ficou assignalado, entre mais significações tem a de abrir mão de um direito.

Ora o credor hypothecario pode remittir uma hypotheca como quem pode remittir qualquer obriga- 
ção, como o credor pignoraticio pode remittir o penhor, como o chirographario pode remittir o direito de cobrar o chirographo.

Como chamaremos nós esse acto do credor que abre mão da garantia hypothecaria, da garantia pignoraticia ou que abre mão do proprio direito de exigir a divida?

Necessariamente havemos de chamar remissão da hypotheca, do penhor, da divida chirographica, etc. etc.

Insistimos na pergunta:

Remissão da hypotheca neste caso tem algo que ver com remissão da hypotheca, titulo ou epigraphe das leis sobre este assumpto?

Nada, absolutamente nada tem que ver. São factos juridicos que nem de longe se relacionam. Um oceano de permeio.

Logo este só erro, esta só confusão, este só cochilo de tão competentes Homeros bastaria sem mais reflexão para desterrarmos de vez das nossas leis e dos nossos commentarios a phrase-remissão da hypotheca, e substituirmos expurgação, liberamento, resgate, redempção.

Este erro, que não será jamais assas vituperado, este erro em má hora introduzido na nossa phraseologia juridica, tem já produzido raizes.

Conhecemos um exemplo de notabilissimo advogado, incumbido de promover procesșo de expurgação ou liberamento de hypotheca, o qual referindo-se ao adquirinte que comprára o predio gravado e ia remil-o, usava destes dizeres incorrectos: $-O$ remittente offerece o preço de. em vez de escrever o rediminte ou redemptor offerece o preço de. 
Quem vai expurgar o seu predio é redemptor, é resgatante, nunca remittente.

Remittente é o que remitte, é o que renuncia ou relaxa ou não exige.

Baste o que fica dicto como um clamor aos ceos dos homens doutos.

Repitamos com sciencia e consciencia o pensamento conceituosissimo de Boileau posto em vernaculo por Castilho:

"Em summa, sem a lingua, o mais divino auctor,

"Faça elle o que fizer, é pessimo escriptor.»

S. Paulo-Agosto de 96.

Dr. R. Correa da Silva. 